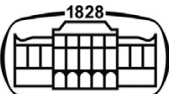

AKADÉMIAI KIADÓ

Journal of Behavioral Addictions

9 (2020) 4, 1068-1078

DOI:

$10.1556 / 2006.2020 .00093$

(c) 2020 The Author(s)

\section{FULL-LENGTH REPORT}

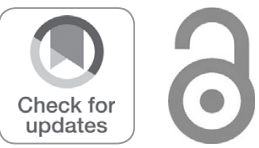

\title{
Problematic shopping and self-injurious behaviors in adolescents
}

\author{
NORMAN R. GREENBERG ${ }^{1}, \mathrm{ZU}_{\mathrm{U}}$ WEI ZHAI ${ }^{2,3}, \mathrm{RANI} A . \mathrm{HOFF}^{3}$, \\ SUCHITRA KRISHNAN-SARIN ${ }^{3}$ and \\ MARC N. POTENZA ${ }^{3,4,5,6,7 *}$
}

\author{
${ }^{1}$ Yale School of Medicine, New Haven, CT, USA \\ ${ }^{2}$ Program in Neuroscience, Middlebury College, Middlebury, VT, USA \\ ${ }^{3}$ Department of Psychiatry, Yale School of Medicine, New Haven, CT, USA \\ ${ }^{4}$ Connecticut Mental Health Center, New Haven, CT, USA \\ ${ }^{5}$ Connecticut Council on Problem Gambling, Wethersfield, CT, USA \\ ${ }^{6}$ Child Study Center, Yale School of Medicine, New Haven, CT, USA \\ ${ }^{7}$ Department of Neuroscience, Yale University, New Haven, CT, USA
}

Received: June 19, 2020 • Revised manuscript received: September 27, 2020; October 30, 2020 - Accepted: October 30, 2020 Published online: December 8, 2020

\begin{abstract}
Background and aims: Self-injurious behaviors (SIBs) and problematic shopping (PS) are both prevalent in adolescents. These behaviors have been proposed as behavioral addictions and linked to impulsivity (Imp) and sensation-seeking (SS). They are also associated with negative mental health and psychosocial measures. This study examined relationships between PS and SIB in adolescents. It also examined how PS and SIB relate to Imp and SS, and interactions between PS and SIB in relation to health/functioning measures. Methods: Survey data from 2,624 Connecticut high-school students were evaluated using chi-square analyses. Next, logistic regression models were used to assess relationships between PS and measures of SIB. T-tests compared Imp and SS in adolescents with and without PS and SIB. Interaction analyses assessed effects of PS on relationships between SIB and health/functioning measures. Results: Adolescents with PS had 3.43-fold higher odds of endorsing lifetime SIB than those without PS, and were more likely to exhibit severe SIB and disruption due to SIB. PS and SIB were associated with elevated Imp and SS. Interaction analyses revealed that in adolescents with PS, the relationships between SIB and substance use was weaker than in adolescents without PS. This suggests PS accounts for variance in relationships between SIB and substance use. Discussion and conclusions: PS is strongly related to SIB prevalence, severity, and impairment in adolescents, and weakens associations between SIB and substance use. PS should therefore be considered for prevention efforts for SIB. Further research should investigate mechanisms connecting PS and SIB and explore possible interventions targeting associated features like Imp and SS.
\end{abstract}

\section{KEYWORDS}

self-injurious behaviors, problematic shopping, compulsive buying, non-suicidal self-injury, addictive behaviors, impulsivity

\section{INTRODUCTION}

Corresponding author.

Non-suicidal self-injurious behavior (SIB) is the infliction of harm to one's own body without suicidal intent. SIB may include cutting, burning, biting, severely scratching, or harming oneself in another way (Madge et al., 2008). SIB is a strong predictor of future suicidal behavior and is associated with significant impairment including depression, anxiety, substance use, poor academic achievement, interpersonal conflict, and economic burdens (Hawton, Rodham, Evans, 
\& Weatherall, 2002; Hawton et al., 2015; Kinchin \& Doran, 2017; Moran et al., 2012). This makes SIB an area of important research and prevention efforts.

While some debate has existed surrounding how best to conceptualize SIB, researchers have recognized the addictive elements of repetitive engagement in SIB and the use of SIB for emotional modulation (Blasco-Fontecilla et al., 2016; Favazza \& Rosenthal, 1993; Worley, 2020). Nixon et al. found that hospitalized adolescents with repetitive SIB experienced urges and tension relieved only by SIB, preoccupation with SIB, and difficulty cutting back on SIB despite negative consequences, which are characteristic of addictions (Nixon, Cloutier, \& Aggarwal, 2002). SIB has also been found to co-occur with substance use disorders in hospitalized patients, as well as with behavioral addictions like gambling disorder in community samples (Chai et al., 2020; Farhat et al., 2020). In addition to having potentially addictive features related to repetitive engagement, SIB has been recognized as a way to modify negative emotions, cope with negativity, and provide feelings of excitement and exhilaration (Edmondson, Brennan, \& House, 2016).

Problematic shopping (PS), or compulsive buying, is defined by frequent and impulsive shopping episodes, which often follow strong urges to shop and result in negative psychosocial and financial consequences (Koran, Faber, Aboujaoude, Large, \& Serpe, 2006). PS has not been recognized as its own disorder in the Diagnostic and Statistical Manual Fifth Edition (DSM-5) or the eleventh revision of the International Classification of Diseases (ICD-11), and this has been reported to reflect insufficient data for establishing diagnostic criteria (Lejoyeux \& Weinstein, 2010). However, it has been proposed to be considered as an "other specified disorder due to addictive behaviors" within the ICD-11 (Brand et al., 2020). Researchers have distinguished PS episodes from other shopping episodes by the characteristic preoccupation about shopping, exhilaration and relief following purchases, and subsequent shame or guilt (McElroy, Keck, Pope, Smith, \& Strakowski, 1994; Miltenberger et al., 2003; Müller et al., 2012; Schlosser, Black, Repertinger, \& Freet, 1994). PS is also distinguished by its association with negative health and psychosocial factors, including antisocial behavior, substance use, large debts, and interpersonal conflicts, making it another subject of important investigation (Schlosser et al., 1994; Grant, Potenza, Krishnan-Sarin, Cavallo, \& Desai, 2011).

SIB and PS share several characteristics. Similar to SIB, PS has been described within an addiction framework. People with PS often experience craving and urges for shopping, poor control over spending, and persistent engagement in shopping despite negative consequences (Müller, Mitchell, \& de Zwaan, 2015). PS has also been linked to behavioral addictions, like gambling disorder (Yip et al., 2015). Also similar to SIB, PS has been recognized as a way to manage negative emotions, to provide mood elevation in the context of negative emotions, and to generate excitement and exhilaration (Miltenberger et al., 2003).

Additionally, PS and SIB are both linked to aspects of impulsivity (Imp) and sensation-seeking (SS). Impulsivity is a multidimensional characteristic that includes the tendency to act rashly with limited premeditation (lack of premeditation), the tendency to act rashly in response to negative or positive emotions (negative and positive urgency, respectively), and the tendency to abandon goaldirected behaviors (lack of perseverance) (Lockwood, Daley, Townsend, \& Sayal, 2017). SS refers to the preference for intense, novel or risky experiences (Lockwood et al., 2017). Lack of premeditation and negative urgency have been associated with SIB in undergraduates, and SS in an LGBT sample was associated with a higher prevalence of SIB (Liu \& Mustanski, 2012; Taylor, Peterson, \& Fischer, 2012). PS has also been associated with Imp, including lack of premeditation, lack of perseverance, negative urgency and SS in community samples (Billieux, Rochat, Rebetez, \& Van der Linden, 2008; Lejoyeux, Arbaretaz, McLoughlin, \& Ades, 2002). Taken together, these data suggest that Imp and SS may relate importantly to both PS and SIB.

Adolescence, the period between childhood and early adulthood that includes high-school years, is a stage of development characterized by elevated rates of Imp and risktaking behaviors (Potenza, 2013). This makes it a time of particular vulnerability to addictive behaviors or maladaptive behaviors for modulating emotions (Potenza, 2013). Fittingly, SIB, which has been linked to poor emotional regulation, exhilaration, and addictive features, has a higher prevalence in adolescents than in adults. While estimates vary between studies, lifetime prevalence of SIB in community samples of adolescents ages 12-17, have been between 15 and $20 \%$, in contrast to community samples of adults with estimates of $5.9 \%$ (Heath, Schaub, Holly, \& Nixon, 2008; Klonsky, 2011). Similarly, most people with PS report that their PS began in late adolescence or in their early twenties, when Imp and risk-taking behavior are elevated (Christenson et al., 1994; Koran, Bullock, Hartston, Elliott, \& D'Andrea, 2002).

Due to the similar functions, characteristics, and links to Imp of PS and SIB, we sought to understand the relationship between the two behaviors. We examined the behaviors in adolescents because of the prevalence of PS and SIB in adolescence and the potential negative impacts on development. Previous studies investigating the relationship between SIB and shopping behaviors have demonstrated mixed results. One study did not find a significant difference in rates of SIB between a group of 31 people with PS and a group of 31 without PS (Zander, Claes, Voth, de Zwaan, \& Müller, 2016). A study of 372 adult females found that patients with PS had higher mean scores on a self-harm inventory for borderline personality disorder, but did not assess for the prevalence, frequency or severity of self-harm in the sample (Sansone, Chang, Jewell, Sellbom, \& Bidwell, 2013). Another study of 1,122 adults in a primary care setting found that patients who endorsed "spending more than they have" exhibited higher scores on the borderline personality disorder self-harm inventory, although this study did not formally assess for PS (Sansone \& Wiederman, 2012). While these studies have established an association 
between shopping behaviors and mean numbers of selfharm methods in those who engage in self-harm, no studies have established the relationship between PS and likelihood of lifetime SIB, frequency of SIB, or severity of SIB. Additionally, no studies have investigated the two behaviors in adolescents. Lastly, despite the negative impacts of both behaviors, no studies have examined the interactions of SIB and PS with respect to their impact on health and functioning.

To address this knowledge gap, we analyzed survey data from high-school students in Connecticut about their engagement in PS, SIB, and other activities. Because of the similar functions and features of PS and SIB, we hypothesized that PS would be associated with SIB (Edmondson et al., 2016). Additionally, because both behaviors may have addictive components, we hypothesized that PS would be associated with urges for SIB, tension relieved by SIB, and attempts to reduce SIB. We also hypothesized that PS would be associated with increased frequency of SIB and measures of severity of SIB, including hospitalizations due to SIB and self-reported problems of excessive SIB (Müller et al., 2015; Nixon et al., 2002). Next, we hypothesized that because PS and SIB have been linked to Imp and SS, adolescents with PS and adolescents with SIB would have higher Imp and SS than those without PS and SIB, respectively (Lejoyeux \& Weinstein, 2010; Lockwood et al., 2017). Lastly, we performed exploratory analyses to investigate whether relationships between SIB and health/functioning measures differed between adolescents with PS and without PS.

\section{METHODS}

\section{Participants}

This study analyzed cross-sectional survey data from public high-school students in Connecticut. Data were collected in 2006. The methodology used for the survey has been described extensively in previous reports (Desai, Maciejewski, Pantalon, \& Potenza, 2005; Yip et al., 2011). Briefly, all public high schools in Connecticut were invited to participate, and notified of the risk behaviors being assessed. Parents were notified by mail of the survey and how to deny permission for their child to participate. In cases where parents did not make contact, permission was implied. Research staffs were on site to explain, distribute, and collect the surveys, answer any questions, and notify students that participation was fully voluntary. No compensation was given to the participants of the survey (a pen that participants could keep was provided).

Survey data were collected from 4,523 students with a 154-item questionnaire, with questions about risky behaviors including SIB, PS, gambling, and other measures. Of the 4,523 students surveyed, 2,624 (900 males, 1,724 females) were included in the study. Exclusion criteria for the study included omitting questions about shopping behavior $(n=$ 1738), SIB $(n=70)$, and sociodemographic information ( $n$ $=92$ ). The final sample included: $74.28 \%$ White/Caucasian
( $n=1949), 7.39 \%$ Black/African American $(n=194)$, $3.32 \%$ Asian $(n=87), 8.77 \%$ Hispanic $(n=230)$, and $6.25 \%$ other $(n=164$; including Native American, Pacific Islander, and Middle Eastern). Within the sample, the ages of the respondents were as follows: $2.5 \%$ were $<14$ years $(n=66)$, $96.7 \%$ were $14-18$ years $(n=2,538)$, and $0.7 \%$ were $>18$ years $(n=18)$.

\section{Measures}

Sociodemographic information. Sociodemographic information asked in the survey include gender, grade-level, age, race/ethnicity, and family structure.

Self-injurious behaviors. SIB was measured as previously (Farhat et al., 2020). Lifetime SIB was assessed by the question: "Have you ever intentionally (i.e., on purpose) cut your wrists, arms, or other areas of your body or done anything else to hurt yourself (e.g., burned, bit, or severely scratched) without intending to kill yourself?". Participants who answered "yes" were included in the SIB group and those who answered "no" were included in the non-SIB group. Those in the SIB group were asked about their frequency of SIB with the question: "In a typical week, how many times do you hurt yourself in this way?". Answers to the question were grouped into the categories: $<1$ time per week, 1-3 times per week, 4-7 times per week, and $>7$ times per week. The frequency of SIB was considered as an ordered factor for proportional odds cumulative multinomial regression analysis.

Individuals in the SIB group were also asked a series of "yes" or "no" questions to further characterize their engagement in SIB: (1) "Have you ever tried to reduce the amount or number of times you hurt yourself?", (2) "Has a family member ever expressed concern about you hurting yourself?", (3) "Have you ever missed school, work, or other important social activities because you had hurt yourself?", (4) "Do you think you have a problem with hurting yourself?", (5) "Have you ever experienced an irresistible urge or uncontrollable need to hurt yourself?", (6) "Have you ever experienced a growing tension or anxiety that can only be relieved by hurting yourself?", and (7) "Has this behavior ever resulted in hospitalization or injury severe enough to require medical treatment?".

Problematic shopping. Problematic shopping behaviors were assessed as previously (Grant et al., 2011). Participants were asked six "yes" or "no" questions: (1) "Have you even tried to cut back on shopping?", (2) "Has a family member ever expressed concern about the amount of time you shop or the amount of money you spend shopping?", (3) "Have you ever missed school, work, or other important social activities because you were shopping?", (4) "Do you think you have a problem with excessive shopping?", (5) "Have you ever experienced an irresistible urge or uncontrollable need to shop?", and (6) "Have you ever experienced a growing tension or anxiety that can only be relieved by shopping?". Questions (1), (5), and (6) were derived from the Minnesota Impulsive 
Disorders Inventory (MIDI), a valid and reliable instrument for assessing PS in adolescents and adults (Grant, 2008; Grant, Levine, Kim, \& Potenza, 2005; Grant, Williams, \& Potenza, 2007; Grant et al., 2011). As previously (Grant et al., 2011), participants who endorsed all three of the MIDI-based questions, were included in the PS group, and those who did not endorse all three questions were classified as non-PS.

Impulsivity-related measures. Impulsivity and SS characteristics were assessed with the Zuckerman-Kuhlman Personality Questionnaire, a valid and reliable tool for the evaluation of Imp and SS (Gomà-i-Freixanet, Valero, Puntí, \& Zuckerman, 2004; Zuckerman, Kuhlman, Joireman, Teta, \& Kraft, 1993). The questionnaire consists of 19 true or false questions, eight of which assess Imp, including lack of premeditation and lack of perseverance. Negative urgency, or rashness in the context of negative emotions, was not specifically assessed. However, the tendency to act rashly was broadly assessed. Examples of the Imp questions include: (1) "I usually think about what I am going to do before doing it" (reverse scored), and (2) "I often do things on impulse." Eleven of the questions assess SS characteristics. One example of the SS questions is: "I sometimes do "crazy" things just for fun." A sum score from 0 to 8 was determined for Imp, SS from 0 to 11 , and a combined Impulsivity/Sensation-Seeking (ImpSS) score from 0 to 19.

Health/functioning. Health and functioning were assessed as previously (Yip et al., 2011). Engagement in extracurricular activities was assessed by asking about participation in church activities, community service, school clubs and team sports. Participants who endorsed any of the extracurricular activities were compared to those that did not endorse any extracurricular activities. Presence of lifetime marijuana and drug use were assessed. Grade average, frequency of smoking, frequency of alcohol use, and frequency of caffeine use were assessed. Dysphoria/depression was assessed by asking: "During the past 12 months, did you ever feel so sad or hopeless almost every day for two weeks or more in a row that you stopped doing some usual activities?". Notably, valid screens were not used for the assessment of some health and functioning, although efforts were made to use items employed in other youth surveys (e.g., the Youth Risk Behavior Survey) to promote comparability across studies.

\section{Statistical analysis}

Statistical analyses were performed using R. Sociodemographic differences between the SIB and non-SIB, and the PS and non-PS groups were assessed using Chi-squared analyses. Proportional odds cumulative multinomial logistic regression was used to determine the relationship between PS status and SIB frequency. Binomial logistic regressions were performed to determine the relationship between PS status and presence of lifetime SIB and the remaining SIB measures. Binomial logistic regressions were performed to determine the relationship between endorsement of each measure of PS behavior and lifetime SIB. Welch's $t$-tests were performed to compare Imp, SS, and ImpSS scores between the PS and non-PS groups and SIB and non-SIB groups. Lastly, exploratory binomial and baseline-comparison multinomial logistic regressions were performed to determine whether the relationships between SIB and different health and psychosocial measures differed between adolescents with and without PS. All regression models adjusted for gender, race/ethnicity, grade level and family structure. Odds ratios (ORs) with 95\% confidence intervals (95\%CIs) were calculated for each model. Models in which 95\%CIs did not overlap with 1 were considered significant.

\section{ETHICS}

The high-school survey was approved by the Yale School of Medicine IRB. Passive consent procedures were adopted for parental consent, and procedures were in accordance with the Declaration of Helsinki (2013).

\section{RESULTS}

\section{Sociodemographics}

Differences in sociodemographic characteristics between the SIB and non-SIB groups are reported in Table 1. Among the 2,624 participants, 482 (18.37\%) reported SIB. The SIB group consisted of 116 males and 366 females. A larger proportion of females $(75.93 \%)$, relative to males $(24.07 \%)$, were in the SIB group, compared to the non-SIB group (63.40\% female, $36.60 \%$ male). Additionally, a larger percentage of adolescents in the SIB group reported living in a single-parent household or "other" household without two parents (29.05 and 7.88\% respectively) than those in the non-SIB group (21.76 and $4.30 \%$ respectively). Lastly, the percentage of 9th graders compared to 10th, 11th, and 12th graders in the SIB group $(36.72 \%)$, was higher than the percentage of 9th graders within the non-SIB group (29.13\%).

Table 2 displays the sociodemographic differences between adolescents in the PS group and the non-PS group. The PS group $(n=107)$ included 69 females and 38 males. Within the PS, the percentages of those who reported being part of singleparent or other non-two-parent households (27.10 and 9.35\% respectively) were higher than the corresponding percentages in the non-PS group (22.92 and $4.77 \%$ respectively). Within the PS group, the percentages of those in 11th and 12th (33.64 and $23.36 \%$ respectively) grade were larger than the percentages of those in 11th and 12th grade within the non-PS group (26.38 and $15.06 \%$ respectively). Lastly, within the PS group, the percentage of those with SIB $(49.53 \%)$ was higher than that within the non-PS group (17.04\%).

\section{SIB, PS, and Imp-related measures}

Table 3 displays characteristics relating to SIB in adolescents with PS and non-PS. Adolescents with PS, relative to those without PS, were more likely to report lifetime SIB (OR = $3.43,95 \%$ CI $[2.19,5.37])$. Additionally, in adolescents with SIB, those with PS were more likely to report attempts to reduce $\mathrm{SIB}(\mathrm{OR}=7.32,95 \% \mathrm{CI}[3.28,16.33])$, perceived 
Table 1. Chi-square analysis of sociodemographic characteristics of adolescents stratified by self-injurious behavior

\begin{tabular}{|c|c|c|c|c|c|c|c|c|}
\hline \multirow[b]{2}{*}{ Dependent variable } & \multicolumn{2}{|c|}{$\begin{array}{l}\text { Total sample } \\
(N=2,624)\end{array}$} & \multicolumn{2}{|c|}{$\begin{array}{c}\text { Non-self-injurious } \\
\text { Behavior } \\
(N=2,142)\end{array}$} & \multicolumn{2}{|c|}{$\begin{array}{c}\text { Self-injurious } \\
\text { behavior }(N=482)\end{array}$} & \multirow[b]{2}{*}{$\chi^{2}$} & \multirow[b]{2}{*}{$P$} \\
\hline & $N$ & $\%$ & $N$ & $\%$ & $N$ & $\%$ & & \\
\hline Gender & & & & & & & 26.88 & $<0.001$ \\
\hline Male & 900 & $34.30 \%$ & 784 & $36.60 \%$ & 116 & $24.07 \%$ & & \\
\hline Female & 1724 & $65.70 \%$ & 1,358 & $63.40 \%$ & 366 & $75.93 \%$ & & \\
\hline \multicolumn{9}{|l|}{ Race/ethnicity } \\
\hline Caucasian & & & & & & & $<0.001$ & 1.00 \\
\hline No & 675 & $25.72 \%$ & 551 & $25.72 \%$ & 124 & $25.73 \%$ & & \\
\hline Yes & 1949 & $74.28 \%$ & 1,591 & $74.28 \%$ & 358 & $74.27 \%$ & & \\
\hline African-American & & & & & & & 1.40 & 0.24 \\
\hline No & 2,430 & $92.61 \%$ & 1977 & $92.30 \%$ & 453 & $93.98 \%$ & & \\
\hline Yes & 194 & $7.39 \%$ & 165 & $7.70 \%$ & 29 & $6.02 \%$ & & \\
\hline Asian & & & & & & & 0.50 & 0.48 \\
\hline No & 2,537 & $96.68 \%$ & 2074 & $96.83 \%$ & 463 & $96.06 \%$ & & \\
\hline Yes & 87 & $3.32 \%$ & 68 & $3.17 \%$ & 19 & $3.94 \%$ & & \\
\hline Hispanic & & & & & & & 0.57 & 0.45 \\
\hline No & 2,394 & $91.23 \%$ & 1959 & $91.46 \%$ & 435 & $90.25 \%$ & & \\
\hline Yes & 230 & $8.77 \%$ & 183 & $8.54 \%$ & 47 & $9.75 \%$ & & \\
\hline Other & & & & & & & 0.02 & 0.90 \\
\hline No & 2,460 & $93.75 \%$ & 2007 & $93.70 \%$ & 453 & $93.98 \%$ & & \\
\hline Yes & 164 & $6.25 \%$ & 135 & $6.30 \%$ & 29 & $6.02 \%$ & & \\
\hline Grade & & & & & & & 10.81 & 0.01 \\
\hline 9th & 801 & $30.53 \%$ & 624 & $29.13 \%$ & 177 & $36.72 \%$ & & \\
\hline 10th & 719 & $27.40 \%$ & 600 & $28.01 \%$ & 119 & $24.69 \%$ & & \\
\hline 11th & 700 & $26.68 \%$ & 584 & $27.26 \%$ & 116 & $24.07 \%$ & & \\
\hline 12 th & 404 & $15.40 \%$ & 334 & $15.59 \%$ & 70 & $14.52 \%$ & & \\
\hline Family structure & & & & & & & 25.76 & $<0.001$ \\
\hline One parent & 606 & $23.09 \%$ & 466 & $21.76 \%$ & 140 & $29.05 \%$ & & \\
\hline Two parents & 1888 & $71.95 \%$ & 1,584 & $73.95 \%$ & 304 & $63.07 \%$ & & \\
\hline Other & 130 & $4.95 \%$ & 92 & $4.30 \%$ & 38 & $7.88 \%$ & & \\
\hline
\end{tabular}

problems with SIB (OR $=3.11,95 \% \mathrm{CI}[1.72,5.62])$, family concern about their SIB $(\mathrm{OR}=3.11,95 \% \mathrm{CI}[1.72,5.62])$, missing work, school, or social activities due to SIB (OR = $3.32,95 \% \mathrm{CI}[1.82,6.05])$, irresistible urges or uncontrollable need for SIB $(\mathrm{OR}=2.57,95 \% \mathrm{CI}[1.40,4.69])$, growing tension and anxiety only relieved by SIB (OR $=4.11,95 \% \mathrm{CI}$ $[2.19,7.71])$, and hospitalization or medical care resulting from SIB $(\mathrm{OR}=3.31,95 \% \mathrm{CI}[1.68,6.51])$. However, PS status was not associated with frequency of SIB.

The differences in the likelihoods of lifetime SIB between adolescents endorsing and denying each shopping measure are displayed in Table 4. An increased likelihood of lifetime SIB was found in adolescents who reported attempts to reduce shopping behavior $(\mathrm{OR}=1.34,95 \% \mathrm{CI}[1.03-1.75])$, family concern about shopping $(\mathrm{OR}=1.39,95 \% \mathrm{CI}[1.09-1.77])$, missing school, work, or social activities due to shopping (OR $=1.53,95 \% \mathrm{CI}[1.18-1.98])$, a perceived problem with shopping $(\mathrm{OR}=2.99,95 \% \mathrm{CI}[2.15-4.15])$, irresistible urges for shopping $(\mathrm{OR}=1.96,95 \% \mathrm{CI}[1.55-2.49])$, and tension relieved only by shopping $(\mathrm{OR}=2.13,95 \% \mathrm{CI}[1.64-2.78])$.

Table 5 displays results from Welch's t-tests comparing Imp, SS, and ImpSS scores in adolescents with and without PS and SIB. Adolescents with PS and adolescents with SIB displayed higher Imp, SS, ImpSS scores than adolescents without PS and without SIB, respectively.

\section{SIB health correlates and PS}

Table 6 displays results from exploratory analyses of relationships between SIB and health measures across PS groups. Interaction ORs with SIB and PS indicated that the associations between SIB and lifetime marijuana use (interaction OR $=0.35,95 \% \mathrm{CI}[0.15,0.84]$ ), occasional smoking (interaction $\mathrm{OR}=0.38,95 \% \mathrm{CI}[0.15,0.97]$ ), regular smoking (interaction $\mathrm{OR}=0.10,95 \% \mathrm{CI}[0.03,0.33])$, and heavy alcohol use (interaction $\mathrm{OR}=0.24,95 \% \mathrm{CI}[0.07,0.77]$ ) were weakened in the presence of PS. In these cases, statistically non-significant relationships were typically observed in the PS group (Table 6) and significant relationships in the non-PS group. Specifically, significant associations between SIB and lifetime marijuana use (SIB vs. non-SIB OR $=3.09,95 \% \mathrm{CI}[2.45,3.90]$ ), occasional smoking (SIB vs. non-SIB OR $=2.96,95 \%$ CI $[2.28$, 3.85]), regular smoking (SIB vs. non-SIB OR $=7.44,95 \% \mathrm{CI}$ $[5.49,10.10]$ ), and heavy alcohol use (SIB vs. non-SIB OR $=$ $2.94,95 \% \mathrm{CI}[2.07,4.18])$ were observed in the non-PS group.

\section{DISCUSSION}

SIB is particularly prevalent in adolescence, and PS often begins in adolescence (Christenson et al., 1994; Heath et al., 
Table 2. Chi-square analysis of sociodemographic characteristics of adolescents stratified by problematic shopping

\begin{tabular}{|c|c|c|c|c|c|c|}
\hline \multirow[b]{2}{*}{ Dependent variable } & \multicolumn{2}{|c|}{$\begin{array}{c}\text { Non-problematic } \\
\text { shopping }(N=2,517)\end{array}$} & \multicolumn{2}{|c|}{$\begin{array}{l}\text { Problematic shopping } \\
\quad(N=107)\end{array}$} & \multirow[b]{2}{*}{$\chi^{2}$} & \multirow[b]{2}{*}{$P$} \\
\hline & $N$ & $\%$ & $N$ & $\%$ & & \\
\hline Gender & & & & & 0.03 & 0.87 \\
\hline Male & 862 & $34.25 \%$ & 38 & $35.51 \%$ & & \\
\hline Female & 1,655 & $65.75 \%$ & 69 & $64.49 \%$ & & \\
\hline \multicolumn{7}{|l|}{ Race/ethnicity } \\
\hline Caucasian & & & & & 0.20 & 0.66 \\
\hline No & 645 & $25.63 \%$ & 30 & $28.04 \%$ & & \\
\hline Yes & 1872 & $74.37 \%$ & 77 & $71.96 \%$ & & \\
\hline African-American & & & & & 0.05 & 0.82 \\
\hline No & 2,332 & $92.65 \%$ & 98 & $91.59 \%$ & & \\
\hline Yes & 185 & $7.35 \%$ & 9 & $8.41 \%$ & & \\
\hline Asian & & & & & $<0.001$ & 1.00 \\
\hline No & 2,434 & $96.70 \%$ & 103 & $96.26 \%$ & & \\
\hline Yes & 83 & $3.30 \%$ & 4 & $3.74 \%$ & & \\
\hline Hispanic & & & & & 0.15 & 0.70 \\
\hline No & 2,298 & $91.30 \%$ & 96 & $89.72 \%$ & & \\
\hline Yes & 219 & $8.70 \%$ & 11 & $10.28 \%$ & & \\
\hline Other & & & & & 0.01 & 0.94 \\
\hline No & 2,359 & $93.72 \%$ & 101 & $94.39 \%$ & & \\
\hline Yes & 158 & $6.28 \%$ & 6 & $5.61 \%$ & & \\
\hline Grade & & & & & 11.64 & 0.01 \\
\hline 9th & 780 & $30.99 \%$ & 21 & $19.63 \%$ & & \\
\hline 10th & 694 & $27.57 \%$ & 25 & $23.36 \%$ & & \\
\hline 11 th & 664 & $26.38 \%$ & 36 & $33.64 \%$ & & \\
\hline 12 th & 379 & $15.06 \%$ & 25 & $23.36 \%$ & & \\
\hline Family structure & & & & & 6.21 & 0.04 \\
\hline One parent & 577 & $22.92 \%$ & 29 & $27.10 \%$ & & \\
\hline Two parents & 1820 & $72.31 \%$ & 68 & $63.55 \%$ & & \\
\hline Other & 120 & $4.77 \%$ & 10 & $9.35 \%$ & & \\
\hline Self-injurious behavior status & & & & & 70.10 & $<0.001$ \\
\hline Non self-injurious behavior & 2088 & $82.96 \%$ & 54 & $50.47 \%$ & & \\
\hline Self-injurious behavior & 429 & $17.04 \%$ & 53 & $49.53 \%$ & & \\
\hline
\end{tabular}

2008; Koran et al., 2002). Both behaviors have extensive negative impacts on health and functioning and share addictive features (Müller et al., 2015; Nixon et al., 2002). This study is the first to investigate the relationship between PS and several measures of SIB in adolescence, as well as relationships between PS and SIB and various health

Table 3. Adjusted multivariate analysis of self-injurious behavior in adolescents stratified by problematic shopping status

\begin{tabular}{lccc}
\hline & \multicolumn{3}{c}{$\begin{array}{c}\text { Problematic shopping vs. } \\
\text { Non-problematic shopping }\end{array}$} \\
\cline { 2 - 4 } & OR & $95 \%$ CI & $P$ \\
\hline Dependent variable & 3.43 & $2.19-5.37$ & $<0.001$ \\
Lifetime self-injurious behavior & 1.03 & $0.56-1.92$ & 0.92 \\
Self-injurious behavior frequency & & & \\
Self-injurious behavior criteria & 7.32 & $3.28-16.33$ & $<0.001$ \\
$\quad$ Attempt to reduce & 3.11 & $1.72-5.62$ & $<0.001$ \\
Perceived problem & 3.11 & $1.72-5.62$ & $<0.001$ \\
Family concern & 3.32 & $1.82-6.05$ & $<0.001$ \\
Missed school, work, activity & 2.57 & $1.40-4.69$ & 0.002 \\
Irresistible urges for behavior & 4.11 & $2.19-7.71$ & $<0.001$ \\
Tension relieved only by behavior & 4.31 & $1.68-6.51$ & $<0.001$ \\
Hospitalization or medical care & 3.61 & & \\
\hline
\end{tabular}

and functioning measures. PS was associated with higher occurrence and severity of SIB. Additionally, PS and SIB were each associated with Imp and SS characteristics, and PS weakened associations between SIB and several health and functioning correlates. Implications are discussed below.

Table 4. Adjusted multivariate analysis of lifetime self-injurious behavior in adolescents stratified by endorsement of problematic shopping measures

\begin{tabular}{lccc}
\hline & \multicolumn{3}{c}{$\begin{array}{c}\text { Lifetime self-injurious } \\
\text { behavior }\end{array}$} \\
\cline { 2 - 4 } & OR & $95 \%$ CI & $P$ \\
\hline Independent variable & & & \\
Problematic shopping question & 1.34 & $1.03-1.75$ & 0.03 \\
$\quad$ Attempt to reduce & 1.39 & $1.09-1.77$ & 0.01 \\
Family concern & 1.53 & $1.18-1.98$ & 0.001 \\
Missed school, work, activity & 2.99 & $2.15-4.15$ & $<0.001$ \\
Perceived problem & 1.96 & $1.55-2.49$ & $<0.001$ \\
Irresistible urges for behavior & 2.13 & $1.64-2.78$ & $<0.001$ \\
Tension relieved only by behavior & & & \\
\hline
\end{tabular}


Table 5. Welch's t-test for impulsivity and sensation-seeking scores in problematic shopping and self-injurious behavior groups

\begin{tabular}{|c|c|c|c|c|}
\hline & \multicolumn{2}{|c|}{ Mean score } & \multirow[b]{2}{*}{$t$} & \multirow[b]{2}{*}{$P$} \\
\hline & Non-problematic shopping & Problematic shopping & & \\
\hline Impulsivity & 3.42 & 4.39 & 4.83 & $<0.001$ \\
\hline Sensation-seeking & 6.68 & 8.12 & 4.55 & $<0.001$ \\
\hline \multirow[t]{3}{*}{ Impulsivity/sensation-seeking } & 10.07 & 12.56 & 5.34 & $<0.001$ \\
\hline & \multicolumn{2}{|c|}{ Mean score } & & \\
\hline & Non-self-injurious behavior & Self-injurious behavior & $t$ & $P$ \\
\hline Impulsivity & 3.27 & 4.30 & 8.93 & $<0.001$ \\
\hline Sensation-seeking & 6.50 & 7.75 & 8.46 & $<0.001$ \\
\hline Impulsivity/sensation-seeking & 9.75 & 12.03 & 9.64 & $<0.001$ \\
\hline
\end{tabular}

Table 6. Adjusted multivariate analyses of SIB on health/functioning stratified by problematic shopping status

\begin{tabular}{|c|c|c|c|c|c|c|c|c|c|}
\hline \multirow[b]{2}{*}{ Dependent variable } & \multicolumn{3}{|c|}{$\frac{\text { Non-problematic shopping }}{\text { SIB vs. Non-SIB }}$} & \multicolumn{3}{|c|}{$\begin{array}{c}\text { Problematic shopping } \\
\text { SIB vs. Non-SIB }\end{array}$} & \multicolumn{3}{|c|}{$\begin{array}{l}\text { Problematic shopping status (SIB vs. } \\
\text { Non-SIB) vs. Non-problematic } \\
\text { shopping (SIB vs. Non-SIB) interaction }\end{array}$} \\
\hline & OR & $95 \% \mathrm{CI}$ & $P$ & OR & $95 \% \mathrm{CI}$ & $P$ & Interaction $\mathrm{OR}$ & $95 \% \mathrm{CI}$ & $P$ \\
\hline Any extracurricular activities & 0.66 & $0.52-0.84$ & $<0.001$ & 3.11 & $0.90-10.83$ & 0.07 & 2.25 & $0.90-5.60$ & 0.08 \\
\hline \multicolumn{10}{|l|}{ Grade average } \\
\hline A's and B's & \multicolumn{3}{|c|}{ Ref. } & \multicolumn{3}{|c|}{ Ref. } & \multicolumn{2}{|c|}{ Ref. } & \\
\hline C's and lower & 1.95 & $1.55-2.44$ & $<0.001$ & 1.04 & $0.42-2.58$ & 0.94 & 0.62 & $0.27-1.44$ & 0.27 \\
\hline \multicolumn{10}{|l|}{ Substance use } \\
\hline Marijuana use, lifetime & 3.09 & $2.45-3.90$ & $<0.001$ & 1.09 & $0.42-2.85$ & 0.86 & 0.35 & $0.15-0.84$ & 0.02 \\
\hline Other drug use, lifetime & 5.46 & $3.90-7.64$ & $<0.001$ & 3.64 & $0.82-16.06$ & 0.09 & 0.57 & $0.17-1.90$ & 0.36 \\
\hline \multicolumn{10}{|l|}{ Smoking, current } \\
\hline Never & \multicolumn{3}{|c|}{ Ref. } & \multicolumn{3}{|c|}{ Ref. } & \multicolumn{2}{|c|}{ Ref. } & \\
\hline Occasionally & 2.96 & $2.28-3.85$ & $<0.001$ & 1.54 & $0.54-4.38$ & 0.42 & 0.38 & $0.15-0.97$ & 0.04 \\
\hline Regularly & 7.44 & $5.49-10.10$ & $<0.001$ & 0.90 & $0.24-3.48$ & 0.88 & 0.10 & $0.03-0.33$ & $<0.001$ \\
\hline \multicolumn{10}{|l|}{ Alcohol use, current } \\
\hline Never regular & \multicolumn{3}{|c|}{ Ref. } & \multicolumn{3}{|c|}{ Ref. } & \multicolumn{2}{|c|}{ Ref. } & \\
\hline Light & 1.63 & $1.23-2.17$ & $<0.001$ & 0.64 & $0.16-2.61$ & 0.53 & 0.44 & $0.13-1.49$ & 0.19 \\
\hline Moderate & 1.71 & $1.28-2.28$ & $<0.001$ & 0.83 & $0.24-2.84$ & 0.77 & 0.47 & $0.16-1.36$ & 0.16 \\
\hline Heavy & 2.94 & $2.07-4.18$ & $<0.001$ & 0.98 & $0.27-3.59$ & 0.98 & 0.24 & $0.07-0.77$ & 0.02 \\
\hline \multicolumn{10}{|l|}{ Caffeine use } \\
\hline None & \multicolumn{2}{|r|}{ Ref. } & & \multicolumn{3}{|c|}{ Ref. } & \multicolumn{2}{|c|}{ Ref. } & \\
\hline $1-2$ per day & 0.99 & $0.72-1.37$ & 0.96 & 0.44 & $0.12-1.64$ & 0.22 & 0.38 & $0.12-1.21$ & 0.10 \\
\hline $3+$ per day & 1.88 & $1.34-2.63$ & $<0.001$ & 0.91 & $0.23-3.60$ & 0.89 & 0.31 & $0.09-1.02$ & 0.05 \\
\hline Dysphoria/depression & 4.78 & $3.80-6.03$ & $<0.001$ & 5.41 & $2.04-14.33$ & $<0.001$ & 1.08 & $0.44-2.64$ & 0.87 \\
\hline
\end{tabular}

Note: The reference categories are non-SIB and non-PS. "Ref." denotes reference category.

\section{PS and SIB}

Our main finding was that PS was associated with 3.4-fold increased odds of SIB in adolescents. This indicates that PS is strongly related to SIB in this age group. A better understanding of the relationship of PS to SIB is required for the treatment of the two co-occurring behaviors. In the subset of adolescents with SIB, PS was also associated with a higher likelihood of hospitalizations or need for medical care due to SIB, perceived problem with SIB, and family concern related to SIB in adolescents with PS. This situation suggests that PS may not only increase the risk of initiating SIB, but also affect the morbidity of SIB in adolescents. While the exact mechanisms linking the two behaviors are currently unknown, some possibilities are proposed below.

First, PS and SIB may share features of behavioral addictions. In this study, adolescents with PS were more likely to experience the addictive features of SIB, including urges for SIB, tension relieved only by SIB and attempts to cut back on SIB, than those without PS. This may suggest that PS and SIB may fit into a larger constellation of behavioral addictions and related behaviors, and may share similar neurobiological pathways (Nixon et al., 2002; Piquet-Pessoa \& Fontenelle, 2016).

PS and SIB have also both been described as providing a rush of excitement or exhilaration, and in this study, both were associated with SS characteristics (Edmondson et al., 2016; Lejoyeux \& Weinstein, 2010; McElroy et al., 1994). This finding may indicate that the two behaviors are positively reinforced and coexist in adolescents with SS tendencies. PS and SIB have also been described as helping individuals escape and cope with negative emotions, like depression, anxiety or tension (Miltenberger et al., 2003; 
Müller et al., 2012). Therefore, PS and SIB may also be negatively reinforced in adolescents, in the absence of more adaptive coping mechanisms for modifying emotions. Additionally, the role of negative reinforcement is supported by our findings. Endorsing any of the questions about PS behavior was associated with higher likelihoods of SIB. However, experiencing tension relieved only by shopping or irresistible urges for shopping were some of the most significantly associated with SIB, with an approximate 2 -fold increase in odds of SIB. This finding lends further support to potential roles of negative reinforcement and relief from negative emotions, as important mechanisms connecting the behaviors.

Lastly, our results support previous findings that Imp relates both to PS and SIB, and previous reports have shown that Imp is associated with severe SIB and suicidality (Anestis, Soberay, Gutierrez, Hernández, \& Joiner, 2014; Lockwood et al., 2017). Some have posited that Imp contributes to repetitive engagement in SIB and subsequent habituation to the painful sensations during SIB (Anestis et al., 2014). Hence, it is possible that relationships between more severe SIB and PS may reflect underlying Imp in adolescents with both behaviors. While negative reinforcement, positive reinforcement, underlying addictive and impulsive tendencies are all possible mechanisms by which PS and SIB are related, further investigation is needed. With a better understanding of the link between the two behaviors, interventions could then be developed, targeting SS, Imp, or improving coping skills and stress management, to treat adolescents with both PS and SIB, or to prevent the future co-occurrence of both behaviors in adolescents.

In this study, we failed to find an association between PS and weekly frequency of SIB. This may be due to the small number of adolescents who fulfilled criteria for PS and SIB. Alternatively, there may be no significant association between PS and SIB frequency, in contrast to other measures of SIB impairment and severity. PS may not be associated with higher frequencies of SIB, despite increases in other measures of SIB, because adolescents with SIB and concurrent PS may use PS as a way to cope with negativity or experience sensations of exhilaration, without increasing their frequency of SIB. Further investigations with larger samples are needed to examine further possible relationships between PS and SIB frequency.

\section{PS, SIB, and health and functioning measures}

Consistent with previous studies, among adolescents without PS, strong associations were found between SIB and less involvement in extracurricular activities, poor academic performance, alcohol, tobacco, marijuana, and other substance use, heavy caffeine use, and depression/dysphoria (de Klerk et al., 2011; Kiekens et al., 2016; Moller, Tait, \& Byrne, 2013). Exploratory interaction analyses revealed that among adolescents with PS, weaker relationships were observed between SIB and marijuana, tobacco, and heavy alcohol use. Similar effects have been shown in interactions between PS and problem gambling, in which PS has been found to weaken the association between problem gambling and caffeine and alcohol use (Yip et al., 2015). These findings suggest that PS may account for some of the variance in the relationships between SIB and substance use involving cannabis, tobacco, and alcohol. Adults with PS have been found to experience euphoria, excitement, or a "buzz" during shopping, similar to feelings experienced during marijuana, tobacco and alcohol use (Lejoyeux \& Weinstein, 2010; McElroy et al., 1994). Hence, adolescents with SIB and PS may choose to utilize shopping for mood elevation and excitement, in place of substances like alcohol, marijuana or tobacco, weakening associations between SIB and substance use. However, further research is required to examine this hypothesis directly.

\section{Strengths and limitations}

Strengths of this study of adolescents include the large sample size, the multi-item measures of PS and SIB used, and the range of health measures assessed. However, the study should be considered in the context of limitations. Notably, data were collected in 2006, and changes in shopping behaviors may have occurred, particularly with respect to increases in online shopping. Importantly, SIB and health/functioning measures were generally not assessed using validated instruments; rather, attempts were made to use brief measures employed in other youth surveys (e.g., the Youth Risk Behaviors Survey; https://www.cdc.gov/ healthyyouth/data/yrbs/questionnaires.htm) in order to facilitate comparisons across studies. Future studies should use validated items. The cross-sectional nature of the survey data prevents drawing of causal inferences. The data were also collected from high-school students in Connecticut and may not generalize beyond this region. Further, while the sample size of the study was large, only 107 adolescents were in the PS group, which may have limited the power for some analyses. Additionally, the survey did not assess a full range of motivations for engagement in PS and SIB, limiting our understanding of factors that may link the two behaviors. In addition, while the Imp questionnaire included questions on lack of premeditation, lack of perseverance, and general Imp, correlations of each facet of Imp with PS and SIB were not assessed. Future studies are needed to address these gaps, with particular attention being paid to using validated assessments and more current datasets. Nonetheless, the study lays an important foundation for future investigations in this area.

Funding sources: This work was supported by the National Institute of Health [R01 DA019039, RL1 AA017539]. This project was also supported by the Connecticut Mental Health Center, the Connecticut State Department of Mental Health and Addiction Services, the Connecticut Council on Problem Gambling, and a Center of Excellence in Gambling Research Award from the National Center for Responsible Gaming (now the International Center for Responsible Gaming). The funding agencies had no role in data 
collection or analysis or in the decision to submit the paper for publication.

Authors' contribution: NRG worked with Dr. MNP to conceptualize the study, design analyses and wrote the original draft of the manuscript. NRG conducted the analyses with Drs. MNP and ZWZ advising. Drs. RAH, SK-S, and MNP designed the survey, were involved in funding acquisition, and curated the original data. All authors provided critical feedback with respect to the content of the manuscript. They also had full access to all data in the study and take responsibility for the integrity of the data and the accuracy of the data analysis.

Conflict of interest: The authors report no conflicts of interest with respect to the content of this manuscript. Dr. Potenza has consulted for and advised Game Day Data, the Addiction Policy Forum, AXA, Idorsia and Opiant/Lakelight Therapeutics; received research support from the Veteran's Administration, Mohegan Sun Casino and the National Center for Responsible Gaming (now the International Center for Responsible Gaming); participated in surveys, mailings, or telephone consultations related to drug addiction, impulse-control disorders, or other health topics; consulted for law offices, the federal public defender's office and gambling entities on issues related to impulse-control and addictive disorders; provided clinical care in the Connecticut Department of Mental Health and Addiction Services Problem Gambling Services Program; performed grant reviews for the National Institutes of Health and other agencies; edited journals and journal sections; given academic lectures in grand rounds, CME events, and other clinical/scientific venues; and generated books or chapters for publishers of mental health texts. The other authors report no disclosures. The views presented in this manuscript represent those of the authors and not necessarily those of the funding agencies.

\section{REFERENCES}

Anestis, M. D., Soberay, K. A., Gutierrez, P. M., Hernández, T. D., \& Joiner, T. E. (2014). Reconsidering the link between impulsivity and suicidal behavior. Personality and Social Psychology Review, 18, 366-386. https://doi.org/10.1177/ 1088868314535988.

Billieux, J., Rochat, L., Rebetez, M. M. L., \& Van der Linden, M. (2008). Are all facets of impulsivity related to self-reported compulsive buying behavior? Personality and Individual Differences, 44, 1432-1442. https://doi.org/10.1016/j.paid.2007.12. 011.

Blasco-Fontecilla, H., Fernández-Fernández, R., Colino, L., Fajardo, L., Perteguer-Barrio, R., \& de Leon, J. (2016). The addictive model of self-harming (Non-suicidal and suicidal) behavior. Frontiers in Psychiatry, 7, 8. https://doi.org/10.3389/fpsyt.2016. 00008.
Brand, M., Rumpf, H. J., Demetrovics, Z., Müller, A., Stark, R., King, D. L., et al. (2020). Which conditions should be considered as disorders in the ICD-11 designation of "other specified disorders due to addictive behaviors"? Journal of Behavioral Addictions, Online ahead of print: https://akjournals.com/view/journals/ 2006/aop/article-10.1556-2006.2020.00035/article-10.1556-2006. 2020.00035.xml. https://doi.org/10.1556/2006.2020.00035.

Chai, Y., Luo, H., Wong, G. H. Y., Tang, J. Y. M., Lam, T. C., Wong, I. C. K., et al. (2020). Risk of self-harm after the diagnosis of psychiatric disorders in Hong Kong, 2000-10: A nested casecontrol study. Lancet Psychiatry, 7, 135-147. https://doi.org/10. 1016/s2215-0366(20)30004-3.

Christenson, G. A., Faber, R. J., de Zwaan, M., Raymond, N. C., Specker, S. M., Ekern, M. D., et al. (1994). Compulsive buying: Descriptive characteristics and psychiatric comorbidity. Journal of Clinical Psychiatry, 55, 5-11.

Desai, R. A., Maciejewski, P. K., Pantalon, M. V., \& Potenza, M. N. (2005). Gender differences in adolescent gambling. Annals of Clinical Psychiatry, 17, 249-258. https://doi.org/10.1080/ 10401230500295636.

Edmondson, A. J., Brennan, C. A., \& House, A. O. (2016). Nonsuicidal reasons for self-harm: A systematic review of self-reported accounts. Journal of Affective Disorders, 191, 109-117. https://doi.org/10.1016/j.jad.2015.11.043.

Farhat, L. C., Roberto, A. J., Wampler, J., Steinberg, M. A., Krishnan-Sarin, S., Hoff, R. A., et al. (2020). Self-injurious behavior and gambling-related attitudes, perceptions and behaviors in adolescents. Journal of Psychiatric Research, 124, 7784. https://doi.org/10.1016/j.jpsychires.2020.02.016.

Favazza, A. R., \& Rosenthal, R. J. (1993). Diagnostic issues in selfmutilation. Hospital and Community Psychiatry, 44, 134-140. https://doi.org/10.1176/ps.44.2.134.

Gomà-i-Freixanet, M., Valero, S., Puntí, J., \& Zuckerman, M. (2004). Psychometric properties of the Zuckerman-Kuhlman personality questionnaire in a Spanish sample. European Journal of Psychological Assessment, 20, 134-146. https://doi.org/10. 1027/1015-5759.20.2.134.

Grant, J. E. (2008). Impulse control disorders: A clinician's guide to understanding and treating behavioral addictions. New York, NY, US: W W Norton \& Co.

Grant, J. E., Levine, L., Kim, D., \& Potenza, M. N. (2005). Impulse control disorders in adult psychiatric inpatients. American Journal of Psychiatry, 162, 2184-2188. https://doi.org/10.1176/ appi.ajp.162.11.2184.

Grant, J. E., Potenza, M. N., Krishnan-Sarin, S., Cavallo, D. A., \& Desai, R. A. (2011). Shopping problems among high school students. Comprehensive Psychiatry, 52, 247-252. https://doi. org/10.1016/j.comppsych.2010.06.006.

Grant, J. E., Williams, K. A., \& Potenza, M. N. (2007). Impulse control disorders in adolescent inpatients: Co-occurring disorders and sex differences. Journal of Clinical Psychiatry, 68, 1584-1591. https://doi.org/10.4088/jcp.v68n1018.

Hawton, K., Bergen, H., Cooper, J., Turnbull, P., Waters, K., Ness, J., et al. (2015). Suicide following self-harm: Findings from the multicentre study of self-harm in England, 2000-2012. Journal of Affective Disorders, 175, 147-151. https://doi.org/10.1016/j. jad.2014.12.062. 
Hawton, K., Rodham, K., Evans, E., \& Weatherall, R.. 2002. Deliberate selfharm in adolescents: Self report survey in schools in England. BMJ, 325, 1207-1211. https://doi.org/10.1136/bmj. 325.7374.1207.

Heath, N., Schaub, K., Holly, S., \& Nixon, M. (2008). Self-injury today: Review of population and clinical studies in adolescents. Self-Injury in Youth: The Essential Guide to Assessment and Intervention, 9-27. https://doi.org/10.4324/9780203892671.

Kiekens, G., Claes, L., Demyttenaere, K., Auerbach, R. P., Green, J. G., Kessler, R. C., et al. (2016). Lifetime and 12-month nonsuicidal self-injury and academic performance in college freshmen. Suicide and Life-Threatening Behavior, 46, 563-576. https://doi.org/10.1111/sltb.12237.

Kinchin, I., \& Doran, C. M. (2017). The economic cost of suicide and non-fatal suicide behavior in the Australian workforce and the potential impact of a workplace suicide prevention strategy. International Journal of Environmental Research and Public Health, 14. https://doi.org/10.3390/ijerph14040347.

de Klerk, S., van Noorden, M. S., van Giezen, A. E., Spinhoven, P., den Hollander-Gijsman, M. E., Giltay, E. J., et al. (2011). Prevalence and correlates of lifetime deliberate self-harm and suicidal ideation in naturalistic outpatients: The Leiden Routine Outcome Monitoring study. Journal of Affective Disorders, 133, 257-264. https://doi.org/10.1016/j.jad.2011.03.021.

Klonsky, E. D. (2011). Non-suicidal self-injury in United States adults: Prevalence, sociodemographics, topography and functions. Psychological Medicine, 41, 1981-1986. https://doi.org/10. 1017/s0033291710002497.

Koran, L. M., Bullock, K. D., Hartston, H. J., Elliott, M. A., \& D'Andrea, V. (2002). Citalopram treatment of compulsive shopping: An open-label study. Journal of Clinical Psychiatry, 63, 704-708. https://doi.org/10.4088/jcp.v63n0808.

Koran, L. M., Faber, R. J., Aboujaoude, E., Large, M. D., \& Serpe, R. T. (2006). Estimated prevalence of compulsive buying behavior in the United States. American Journal of Psychiatry, 163, 18061812. https://doi.org/10.1176/ajp.2006.163.10.1806.

Lejoyeux, M., Arbaretaz, M., McLoughlin, M., \& Ades, J. (2002). Impulse control disorders and depression. The Journal of Nervous and Mental Disease, 190, 310-314.

Lejoyeux, M., \& Weinstein, A. (2010). Compulsive buying. The American Journal of Drug and Alcohol Abuse, 36, 248-253. https://doi.org/10.3109/00952990.2010.493590.

Liu, R. T., \& Mustanski, B. (2012). Suicidal ideation and self-harm in lesbian, gay, bisexual, and transgender youth. American Journal of Preventive Medicine, 42, 221-228. https://doi.org/10. 1016/j.amepre.2011.10.023.

Lockwood, J., Daley, D., Townsend, E., \& Sayal, K. (2017). Impulsivity and self-harm in adolescence: A systematic review. European Child \& Adolescent Psychiatry, 26, 387-402. https:// doi.org/10.1007/s00787-016-0915-5.

Madge, N., Hewitt, A., Hawton, K., de Wilde, E. J., Corcoran, P., Fekete, S., et al. (2008). Deliberate self-harm within an international community sample of young people: Comparative findings from the child \& adolescent self-harm in Europe (CASE) study. Journal of Child Psychology and Psychiatry, 49, 667-677. https://doi.org/10.1111/j.1469-7610.2008.01879.x.
McElroy, S. L., Keck, P. E., , Jr., Pope, H. G., , Jr., Smith, J. M., \& Strakowski, S. M. (1994). Compulsive buying: A report of 20 cases. Journal of Clinical Psychiatry, 55, 242-248.

Miltenberger, R. G., Redlin, J., Crosby, R., Stickney, M., Mitchell, J., Wonderlich, S., et al. (2003). Direct and retrospective assessment of factors contributing to compulsive buying. Journal of Behavior Therapy and Experimental Psychiatry, 34, 1-9. https:// doi.org/10.1016/s0005-7916(03)00002-8.

Moller, C. I., Tait, R. J., \& Byrne, D. G. (2013). Deliberate self-harm, substance use, and negative affect in nonclinical samples: A systematic review. Substance Abuse, 34, 188-207. https://doi. org/10.1080/08897077.2012.693462.

Moran, P., Coffey, C., Romaniuk, H., Olsson, C., Borschmann, R., Carlin, J. B., et al. (2012). The natural history of self-harm from adolescence to young adulthood: A population-based cohort study. Lancet, 379, 236-243. https://doi.org/10.1016/s01406736(11)61141-0.

Müller, A., Mitchell, J. E., Crosby, R. D., Cao, L., Johnson, J., Claes, L., et al. (2012). Mood states preceding and following compulsive buying episodes: An ecological momentary assessment study. Psychiatry Research, 200, 575-580. https://doi.org/ 10.1016/j.psychres.2012.04.015

Müller, A., Mitchell, J.E. \& de Zwaan, M. (2015). Compulsive buying. American Journal on Addictions, 24, 132-137. https:// doi.org/10.1111/ajad.12111.

Nixon, M. K., Cloutier, P. F., \& Aggarwal, S. (2002). Affect regulation and addictive aspects of repetitive self-injury in hospitalized adolescents. Journal of the American Academy of Child \& Adolescent Psychiatry, 41, 1333-1341. https://doi.org/10. 1097/00004583-200211000-00015.

Piquet-Pessôa, M., \& Fontenelle, L. F. (2016). Opioid antagonists in broadly defined behavioral addictions: A narrative review. Expert Opinion on Pharmacotherapy, 17, 835-844. https://doi. org/10.1517/14656566.2016.1145660.

Potenza, M. N. (2013). Biological contributions to addictions in adolescents and adults: Prevention, treatment, and policy implications. Journal of Adolescent Health: Official Publication of the Society for Adolescent Medicine, 52, S22-S32. https://doi. org/10.1016/j.jadohealth.2012.05.007.

Sansone, R. A., Chang, J., Jewell, B., Sellbom, M., \& Bidwell, M. (2013). Compulsive buying and borderline personality symptomatology. Journal of Personality Disorders, 27, 260-268. https://doi.org/10.1521/pedi.2013.27.2.260.

Sansone, R. A., \& Wiederman, M. W. (2012). Spending too much: Relationships with borderline personality symptomatology. International Journal of Psychiatry in Clinical Practice, 16, 316318. https://doi.org/10.3109/13651501.2012.693186.

Schlosser, S., Black, D. W., Repertinger, S., \& Freet, D. (1994). Compulsive buying. Demography, phenomenology, and comorbidity in 46 subjects. General Hospital Psychiatry, 16, 205212. https://doi.org/10.1016/0163-8343(94)90103-1.

Taylor, J., Peterson, C. M., \& Fischer, S. (2012). Motivations for self-injury, affect, and impulsivity: A comparison of individuals with current self-injury to individuals with a history of selfinjury. Suicide and Life-Threatening Behavior, 42, 602-613. https://doi.org/10.1111/j.1943-278X.2012.00115.x. 
Worley, J. (2020). Self-injury as an addictive disorder. Journal of Psychosocial Nursing and Mental Health Services, 58, 13-16. https://doi.org/10.3928/02793695-20200513-03.

Yip, S. W., Desai, R. A., Steinberg, M. A., Rugle, L., Cavallo, D. A., Krishnan-Sarin, S., et al. (2011). Health/functioning characteristics, gambling behaviors, and gambling-related motivations in adolescents stratified by gambling problem severity: Findings from a high school survey. American Journal on Addictions, 20, 495-508. https://doi.org/10.1111/j.1521-0391. 2011.00180.x.

Yip, S. W., Mei, S., Pilver, C. E., Steinberg, M. A., Rugle, L. J., Krishnan-Sarin, S., et al. (2015). At-risk/problematic shopping and gambling in adolescence. Journal of Gambling Studies, 31, 1431-1447. https://doi.org/10.1007/s10899-0149494-x.

Zander, H., Claes, L., Voth, E. M., de Zwaan, M., \& Müller, A. (2016). Impulsive behaviors in patients with pathological buying. Journal of Behavioral Addictions, 5, 457-464. https:// doi.org/10.1556/2006.5.2016.050.

Zuckerman, M., Kuhlman, D. M., Joireman, J., Teta, P., \& Kraft, M. (1993). A comparison of three structural models for personality: The Big Three, the Big Five, and the Alternative Five. Journal of Personality and Social Psychology, 65, 757-768. https://doi.org/10.1037/0022-3514.65.4.757. 